\title{
Spectrum of Henoch-Schonlein Purpura in Children: A Single-Center Experience from Western Provence of Saudi Arabia
}

\author{
Esraa M. Bukhari', Khouloud A. Al-Sofyani' ${ }^{1}$, Mohammed Ahmed Muzaffer ${ }^{2 *}$ \\ ${ }^{1}$ King Abdulaziz University Hospital, Jeddah, Saudi Arabia \\ ${ }^{2}$ Department of Pediatrics, Section of Rheumatology, King Abdulaziz University Hospital, Jeddah, Saudi Arabia \\ Email: mmuzaffer@hotmail.com,
}

Received 22 January 2015; accepted 12 February 2015; published 17 February 2015

Copyright (C) 2015 by authors and Scientific Research Publishing Inc.

This work is licensed under the Creative Commons Attribution International License (CC BY).

http://creativecommons.org/licenses/by/4.0/

(c) (i) Open Access

\begin{abstract}
The aim of this study was to describe the common presentation, frequency, and complications of Henoch-Schonlein purpura (HSP) in patients <18 years who were followed up at King Abdulaziz University Hospital, Jeddah over the last 12 years. We performed a retrospective chart review of the medical records of all patients diagnosed as HSP. During this period, only 29 cases were reported (15 males, 14 females), with the mean age at the diagnosis 7.5 years. $82 \%$ percent of the patients had joint involvement in the form of arthritis or arthralgia; $17.2 \%$ had no joint involvement. Abdominal manifestations were reported in $\mathbf{7 2 . 4 \%}$ of the patients, while renal involvement was documented in $\mathbf{2 4 . 1 \%}$ of the cases; two patients had scrotal involvement. Four patients $(13.7 \%)$ had a recurrence within four months of HSP diagnosis. However, all patients had full recovery within a month. More research is warranted to study the prevalence, clinical manifestations, preceding factors, and complications of HSP in a Saudi-based cohort.
\end{abstract}

\section{Keywords}

Children, Diagnosis, Henoch-Schonlein Purpura, Pediatrics, Presentation, Renal Involvement

\section{Introduction}

Vasculitis is the inflammation of the blood vessels. Three main categories of vasculitis have been defined based on the size or histology of the vessel involved: large vessel vasculitis, which includes Takayasu's areteritis; medium vessel vasculitis, which includes polyarteritis nodosa, Kawasaki disease, and cutaneous polyarteritis; and

${ }^{*}$ Corresponding author.

How to cite this paper: Bukhari, E.M., Al-Sofyani, K.A. and Muzaffer, M.A. (2015) Spectrum of Henoch-Schonlein Purpura in Children: A Single-Center Experience from Western Provence of Saudi Arabia. Open Journal of Rheumatology and Autoimmune Diseases, 5, 17-22. http://dx.doi.org/10.4236/ojra.2015.51004 
small vessel vasculitis, which includes granulomatous vasculitis (Wegener's granulomatosis [WG] and ChurgStrauss syndrome) and non-granulomatous vasculitis (microscopic polyangiitis [MPA], Henoch-Schonlein purpura [HSP], cutaneous leukocytoclastic vasculitis, and hypocomplementemic urticarial vasculitis) [1]. Among these, HSP is the commonest form that affects children, with an estimated incidence of 10 to 20 per 100,000 annually [2].

Henoch-Schonlein purpura was first described in 1801 by the physician Heberden and then in 1808 by the dermatologist Willan; however, the condition was named after two German physicians Henoch and his teacher Schonlein in 1837. Schonlein described the association between purpura and arthritis. Then 37 years later, in 1874, Henoch discovered its association with abdominal pain. In 1899, Henoch also described the association between purpura and renal involvement [2].

Henoch-Schonlein purpura is a non-granulomatous small vessel vasculitis that is characterized by deposition of immunoglobulin A (IgA) containing complement component and immune complexes in blood vessel wall as well as the renal mesangium [3].

Currently, HSP diagnosis is mainly clinical, as there are no available laboratory diagnostic tests. The diagnostic criteria for HSP were set by the American College of Rheumatology (ACR) in 1990. These criteria yielded a sensitivity of $87.1 \%$ and specificity of $87.7 \%$ and required the presence of at least two of the following: 1 ) age $\leq$ 20 years at disease onset; 2) palpable purpura; 3) acute abdominal pain; and 4) biopsy showing granulocytes in the walls of small arterioles/venules. A new set of criteria were proposed by the European League against Rheumatism in 2007 (Table 1) [4].

Local studies [5]-[7] have described the clinical presentation of HSP; however, to the best of our knowledge, none of these studies described the HSP presentation in western region of Saudi-based. The aim of this research was to study the frequency and to investigate the clinical presentation of HSP to compare them with different regions of Saudi Arabia.

\section{Methodology}

This was a retrospective chart review of the medical records of all children who were hospitalized for HSP at King Abdulaziz University Hospital, Jeddah, Saudi Arabia between January 2002 and March 2014. Patients were included in the study were $<18$ years old and had a diagnosis of HSP according to the criteria set by the European League against Rheumatism [4]. We excluded all cases in which $>90 \%$ of the data were missing and those with questionable diagnosis of large and medium vessel vasculitis. The study was approved by Biomedical Ethics Research Committee of King Abdulaziz University.

We used the International Classification of Disease 287 (allergic purpura) and D69.2 (other non thrombocytopenic purpura) to identify all cases of HSP. For all patients included in the study, we collected the following data: age, gender, nationality, etiological factors, clinical presentation, management and outcome.

Statistical analysis: Data were analyzed using the Statistical Package for the Social Sciences (SPSS Inc., IL, Chicag, US). Descriptive statistics were computed for all variables. The chi-square test was used to compare different variables. Results are expressed as frequency (percent) and mean (standard deviation [SD]).

\section{Table 1. The diagnostic criteria for HSP were set by the American College of Rheumatology (ACR).}

Purpura or petechiae

and at least one of the following:

1) Abdominal pain

2) Histopathology

3) Acute onset of arthritis or arthralgia

4) Renal involvement
(Mandatory criterion) with lower limb predominance

Typically leukocytoclastic vasculitis with predominant IgA deposit or proliferative glomerulonephritis with predominant IgA deposits.

Defined as joint swelling or joint pain with limitation on motion or joint pain without joint swelling or limitation on motion.

Defined as proteinuria $>0.3 \mathrm{~g} / 24 \mathrm{~h}$ or $>30 \mathrm{mmol} / \mathrm{mg}$ of urine albumin/creatinine ratio on a spot morning sample, hematuria or red blood cell casts $>5$ red blood cells/high power field or red blood cells casts in the urinary sediment or $\geq 2+$ on dipstick. 


\section{Results}

We included 29 patients aged $<18$ years (mean [SD], 7.5 [3.84] years). Of these, 15 were boys, giving a male to female ratio of 1.1:1. Saudis and expatriates comprised approximately equal proportions of the sample (Table 2).

Clinically, all the patients presented with rash; in most cases, patients had petechial rash, with a predilection for the extensor surfaces of the lower limbs. In less than half of the patients $(n=12 ; 41.4 \%)$, upper respiratory tract infection (URTI) preceded the onset of the rash by a few days to one week, whereas half of the cases ( $\mathrm{n}=$ 15; 51.7\%) had fever before the onset of the rash. In two children, tonsillitis was diagnosed one week before HSP diagnosis. Preschool vaccination, herpetic stomatitis, and insect bites were reported to precede onset of the rash in one case each. The mean interval between symptoms and diagnosis was 7.4 (6.9) days.

Eighteen patients (62.1\%) had arthritis; thirteen (72.2\%) had monoarthritis, five (27.7\%) had oligoarthritis and no patient had polyarthritis. Arthralgia was reported in six patients (20.7\%). One 12-year-old boy reported hip and shoulder involvement. None of our patients had small joint involvement. In five cases (17.2\%), there was no joint involvement.

Eleven patients (37.9\%) reported onset of symptoms in winter; seven cases (24.0\%) reported symptom onset in spring and summer, and four (13.8\%) reported onset of symptoms in autumn. Skin biopsy was performed in five cases and consistent with leukocytoclastic vasculitis.

Gastrointestinal tract (GIT) involvement was documented in twenty one cases. Of these cases, twenty patients (68.9\%) had abdominal pain associated with vomiting. Three patients (10.3\%) had nausea. Other GIT involvement included: hematochezia in four cases (13.8\%); occult blood in the stool in two cases (6.9\%); melena one case (3.4\%); and hematemesis one case (3.4\%). No case of hepatosplenomegaly or intussusceptions was recorded.

Renal involvement was reported in seven cases (24.1\%), of which three (10.3\%) manifested as microscopic

\begin{tabular}{|c|c|}
\hline Variable & Number (\%) \\
\hline \multicolumn{2}{|l|}{ Sex } \\
\hline Male & $15(51.7)$ \\
\hline Female & $14(48.3)$ \\
\hline \multicolumn{2}{|l|}{ Nationality } \\
\hline Saudi & $14(48.3)$ \\
\hline Non-Saudi & $15(51.7)$ \\
\hline \multicolumn{2}{|c|}{ Etiological factors } \\
\hline \multicolumn{2}{|l|}{ URTI } \\
\hline Yes & $12(41.4)$ \\
\hline No & $17(58.6)$ \\
\hline \multicolumn{2}{|l|}{ Fever } \\
\hline Yes & $15(51.7)$ \\
\hline No & $14(48.3)$ \\
\hline \multicolumn{2}{|l|}{ Drugs } \\
\hline Yes & $1(3.4)$ \\
\hline No & $28(96.6)$ \\
\hline Others & $5(17.2)$ \\
\hline
\end{tabular}


hematuria; three patients (10.3\%) had high blood pressure, while one (3.4\%) had macroscopic hematuria. Nephritis and acute renal failure were documented in one case (3.4\%) who received cyclophosphamide and corticosteroid pulse therapy. Two cases (6.9\%) reported testicular involvement in the form of scrotal swelling and pain without testicular torsion. Two patients (6.9\%) have neurological manifestations in form of headache, behavioral changes, and irritability. Eleven cases (37.9\%) were treated conservatively. Eighteen patients (62.1\%) received corticosteroids in addition to conservative management for severe abdominal pain, testicular and neurological symptoms. Three patients (10.3\%) required cyclophosphamide besides steroids for nephritic symptoms and renal impairment, and one patient received azathioprine for Nephritic symptoms and prolong purpuric rash (Table 3).

Regarding outcome; four (13.8\%) patients with GIT symptoms have recurrence. However, all patients showed full recovery. None of our patients developed end stage renal disease.

\begin{tabular}{|c|c|c|}
\hline The spectrum of HSP manifestation & Frequency & Percentage \% \\
\hline \multicolumn{3}{|l|}{ Joints } \\
\hline Knee & 13 & 44.8 \\
\hline Ankle & 17 & 58.6 \\
\hline Wrist & 4 & 13.8 \\
\hline Elbow & 7 & 24.1 \\
\hline Hip & 1 & 3.5 \\
\hline Shoulders & 1 & 3.5 \\
\hline Fingers & - & - \\
\hline Toes & - & - \\
\hline \multicolumn{3}{|l|}{ GIT } \\
\hline Abdominal pain & 20 & 69 \\
\hline Nausea & 3 & 10.3 \\
\hline Vomiting & 13 & 44.8 \\
\hline Melena & 1 & 3.4 \\
\hline Hematochezia & 4 & 13.8 \\
\hline Occult blood & 2 & 6.9 \\
\hline Hematemesis & 1 & 3.4 \\
\hline Intussusceptions & - & - \\
\hline \multicolumn{3}{|l|}{ Renal } \\
\hline Microscopic hematuria & 3 & 10.3 \\
\hline Macroscopic hematuria & 1 & 3.4 \\
\hline Nephritic syndrome & 1 & 3.4 \\
\hline Hypertension & 3 & 10.3 \\
\hline Nephrotic syndrome & - & - \\
\hline Acute renal failure & 1 & 3.4 \\
\hline
\end{tabular}




\section{Discussion}

We found that the mean age at the diagnosis of HSP in our cohort was 7.5 years, which is similar to that reported in a cohort of children with HSP at a university hospital in Turkey [8]. Lardhi, 2012 [7], on the other hand reported that the mean age at diagnosis was 6.3 years for patients who were followed up at King Fahad University Hospital in the eastern province of Saudi Arabia. Nevertheless, our finding was similar to that of other authors who reported that the mean age at diagnosis was $8.6 \pm 5$ years in children who consulted at Asir Central Hospital in the southern province of Saudi Arabia [5].

Local studies reported that most patients report onset of HSP symptoms during autumn and winter [6] [7], while al Harbi reported cases in summer [5]. However, symptoms can occur any time throughout the year. On the contrary, most patients in our study reported symptom onset during spring, while some cases were reported in winter. There is no clear explanation for disparit; we believe that some form of bias may have been introduced in our analysis given the small sample size. Upper respiratory tract infections, fever, ingestion of certain drugs, and vaccination have been reported to trigger HSP [9] [10]. In the current study, $41 \%$ of the patients had symptoms of URTI less than one week before the onset of the rash.

In this study, joint involvement occurred in more than $80 \%$ of the cases, either in the form of arthritis (62\%) or arthralgia (20\%). Similar results were reported by other authors, who found that $60 \%$ to $84 \%$ of the patients had articular involvement [11]. In our study we found that the ankles and knees were the most commonly involved joints, followed by elbows and wrists, whereas hip and shoulder involvement was very rare and reported in one case each. Similarly, Lardhi [7], in a study conducted on 78 children with HSP, found that hip and shoulder involvement was reported in only one case each.

In many studies, GIT involvement has been reported in approximately two thirds of patients with HSP [8] [12] which is consistent with our report. Abdominal pain and vomiting with or without nausea were the most frequent symptoms seen in $44.8 \%$ and $10.3 \%$ of our patients, respectively. Both upper and lower GI bleeding can occur with HSP. Hematemesis was reported only in one case out of the 29 patients in this study. Kawasaki [13] reported rare complications, such as intussusception, bowel ischemia, acute appendicitis, pancreatitis, bowel infarction, and intestinal perforation with this disease. However, these rare complications were not seen in our cases.

Renal involvement is an issue of concern amongst patients with HSP, as it may progress to hypertension, nephrotic or nephritic syndromes or renal insufficiency. The percentage of patients who had renal involvement varied between $20 \%$ - 80\% [3] [13] with HSP. In the current study, renal involvement was documented in $24.1 \%$ of the patients. This disparity between our report and those of other authors may be due to lack of renal involvement in the majority of our patients and small number of patients in our study.

Testicular manifestations have been reported in children with HSP. Typically reported symptoms include scrotal swelling or testicular torsion, which clinically manifests as severe acute pain [7]. In this study, only two boys had scrotal pain. An ultrasound examination was performed in these patients to exclude testicular torsion, and the patient's symptoms improved after administration of corticosteroids.

The diagnosis of HSP based on the criteria, no specific test is diagnostic. While there is evidence that laboratory patients with HSP have elevated erythrocyte sedimentation rates, C-reactive protein levels, white blood cell counts, platelet counts and immunoglobulin A levels, none of these tests is specific or diagnostic. In practice, physicians generally perform these tests to exclude bacterial or viral infections or hemorrhagic diseases, which may mimic HSP [2] [14]. These possible causes of vasculitis have been excluded in our patients.

Conservative treatment in form of hydration, bed rest, analgesics and non steroidal anti inflammatory drugs are effective in the majority of the cases, in this study all the patients managed initially conservatively. Although it is beneficial, sometime it is not enough to control the disease symptoms, and more potent anti-inflammatory drugs like corticosteroids are added in the following situations: severe abdominal pain or GI bleeding, severe soft tissue edema, severe scrotal edema, persistent nephrotic syndrome, crescents in more than $50 \%$ of the glomeruli, nurological manifestations and the most rare intrapulmonary hemorrhage [15]. Immunosuppressive medication like Azathioprine and cyclophosphamide found to be effective especially when combined with steroid in severe cases with renal involvement although there is no clinical trial [16]. HSP is usually a self limited disease. In agreement with other studies [3] [13], more than $80 \%$ of our cases showed full recovery, while only four (13.7\%) have a recurrence within 4 months after diagnosis.

This study has limitations that warrant discussion. First, it was hospital-based, single center study. Hence, the 
findings cannot be extrapolated to the western province of Saudi Arabia. Second, the small sample size made it difficult to draw relevant conclusions. We believe that the small number of cases could be because we included only hospitalized patients, who in general, have severe HSP, and patients with mild disease, who are managed at outpatient clinics or the emergency department, were not included in the analysis.

\section{Conclusion}

Although HSP is a self-limited disease, it can lead to long-term morbidity, especially in patients with severe renal involvement. More research is warranted to study HSP, especially in Saudi Arabia, as the prevalence, clinical manifestations, preceding factors, and complications may differ from published data.

\section{References}

[1] Tullus, K. and Marks, S.D. (2009) Vasculitis in Children and Adolescents: Clinical Presentation, Etiopathogenesis, and Treatment. Paediatric Drugs, 11, 375-380. http://dx.doi.org/10.2165/11316120-000000000-00000

[2] Saulsbury, F.T. (2010) Henoch-Schönlein Purpura. Current Opinion in Rheumatology, 22, 598-602. http://dx.doi.org/10.1097/BOR.0b013e32833af608

[3] Trnka, P. (2013) Henoch-Schonlein Purpura in Children. Journal of Paediatrics and Child Health, 49, 995-1003. http://dx.doi.org/10.1111/jpc.12403

[4] Ozen, S., Pistorio, A., Iusan, S.M., Bakkaloglu, A., Herlin, T., Brik, R., Ruperto, N., et al. (2010) EULAR/PRINTO/ PRES Criteria for Henoch-Schonlein Purpura, Childhood Polyarteritis Nodosa, Childhood Wegener Granulomatosis and Childhood Takayasu Arteritis: Ankara 2008. Part II: Final Classification Criteria. Annals of the Rheumatic Disease, 69, 798-806. http://dx.doi.org/10.1136/ard.2009.116657

[5] Al Harbi, N.N. (1996) Henoch-Schoenlein Syndrome in Children: Experience from Southern Part of Saudi Arabia. East African Medical Journal, 73, 191-193.

[6] Al Rasheed, S.A., Abdurrahman, M.B., Al Mugeiren, M.M. and Al Fawaz, I.M. (1991) Henoch-Schönlein Syndrome in Saudi Arabia. Journal of Tropical Pediatrics, 37, 127-130. http://dx.doi.org/10.1093/tropej/37.3.127

[7] Lardhi, A.A. (2012) Henoch-Schonlein Purpura in Children from the Eastern Province of Saudi Arabia. Saudi Medical Journal, 33, 973-978.

[8] Tabel, Y., Inanc, F.C., Dogan, D.G. and Elmas, A.T. (2012) Clinical Features of Children with Henoch-Schonlein Purpura: Risk Factors Associated with Renal Involvement. Iranian Journal of Kidney Disease, 6, 269-274.

[9] Peru, H., Soylemezoglu, O., Bakkaloglu, S.A., Elmas, S., Bozkaya, D., Elmaci, A.M., Kara, F., Buyan, N. and Hasanoglu, E. (2008) Henoch Schonlein Purpura in Childhood: Clinical Analysis of 254 Cases over a 3-Year Period. Clinical Rheumatology, 27, 1087-1092. http://dx.doi.org/10.1007/s10067-008-0868-2

[10] Jennette, J.C. and Falk, R.J. (1997) Small-Vessel Vasculitis. New England Journal of Medicine, 337, 1512-1523. http://dx.doi.org/10.1056/NEJM199711203372106

[11] Mir, S., Yavascan, O., Mutlubas, F., Yeniay, B. and Sonmez, F. (2007) Clinical Outcome in Children with HenochSchönlein Nephritis. Pediatric Nephrology, 22, 64-70. http://dx.doi.org/10.1007/s00467-006-0278-0

[12] Choong, C.K. and Beasley, S.W. (1998) Intra-Abdominal Manifestations of Henoch-Schönlein Purpura. Journal of Paediatrics and Child Health, 34, 405-409. http://dx.doi.org/10.1046/j.1440-1754.1998.00263.X

[13] Kawasaki, Y., Ono, A., Ohara, S., Suzuki, Y., Suyama, K., Suzuki, J. and Hosoya, M. (2013) Henoch-Schönlein Purpura Nephritis in Childhood: Pathogenesis, Prognostic Factors and Treatment. Fukushima Journal of Medical Science, 59, 15-26. http://dx.doi.org/10.5387/fms.59.15

[14] Trapani, S., Micheli, A., Grisolia, F., Resti, M., Chiappini, E., Falcini, F. and De Martino, M. (2005) Henoch Schonlein Purpura in Childhood: Epidemiological and Clinical Analysis of 150 Cases over a 5-Year Period and Review of Literature. Seminars in Arthritis and Rheumatism, 35, 143-153. http://dx.doi.org/10.1016/j.semarthrit.2005.08.007

[15] Weiss, P.F., Klink, A.J., Localio, R., Hall, M., Hexem, K., Burnham, J.M., Keren, R. and Feudtner, C. (2010) Corticosteroids May Improve Clinical Outcomes during Hospitalization for Henoch-Schönlein Purpura. Pediatrics, 126, 674-681. http://dx.doi.org/10.1542/peds.2009-3348

[16] Foster, B.J., Bernard, C., Drummond, K.N. and Sharma, A.K. (2000) Effective Therapy for Severe Henoch-Schonlein Purpura Nephritis with Prednisone and Azathioprine: A Clinical and Histopathologic Study. Journal of Pediatrics, 136, 370-375. http://dx.doi.org/10.1067/mpd.2000.103448 
Scientific Research Publishing (SCIRP) is one of the largest Open Access journal publishers. It is currently publishing more than 200 open access, online, peer-reviewed journals covering a wide range of academic disciplines. SCIRP serves the worldwide academic communities and contributes to the progress and application of science with its publication.

Other selected journals from SCIRP are listed as below. Submit your manuscript to us via either submit@scirp.org or Online Submission Portal.
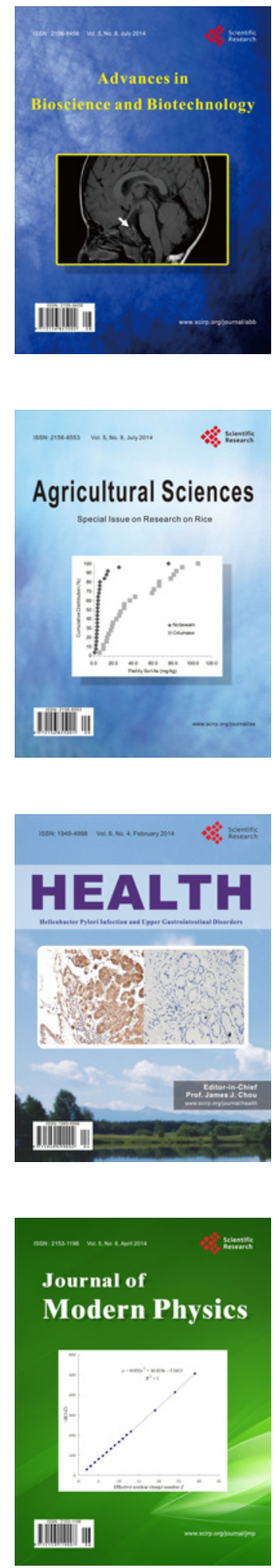
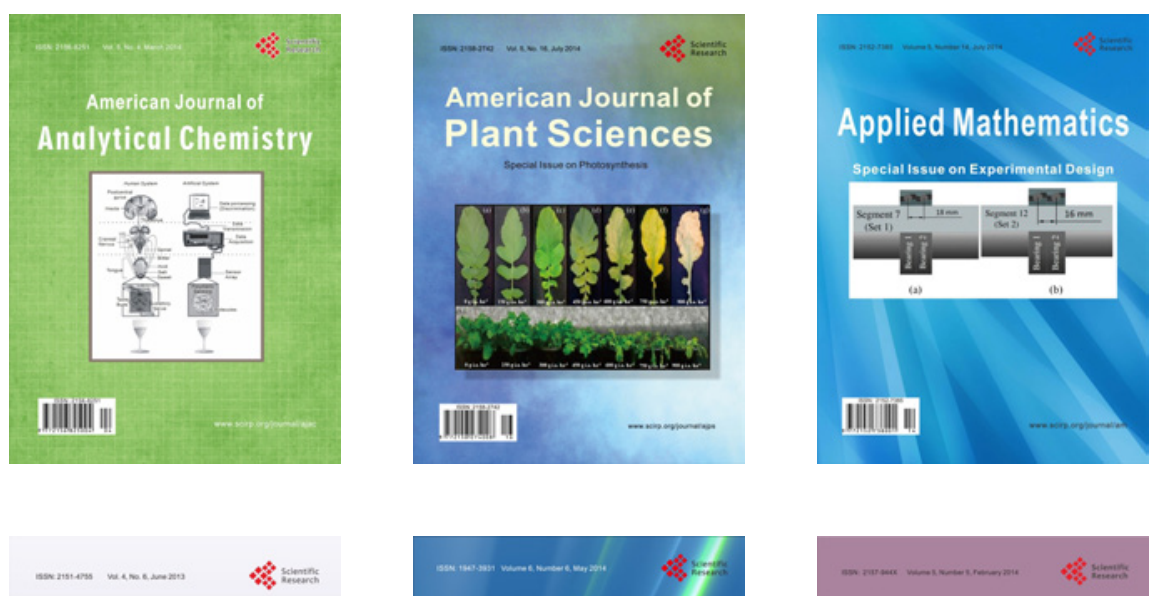

Creative Education
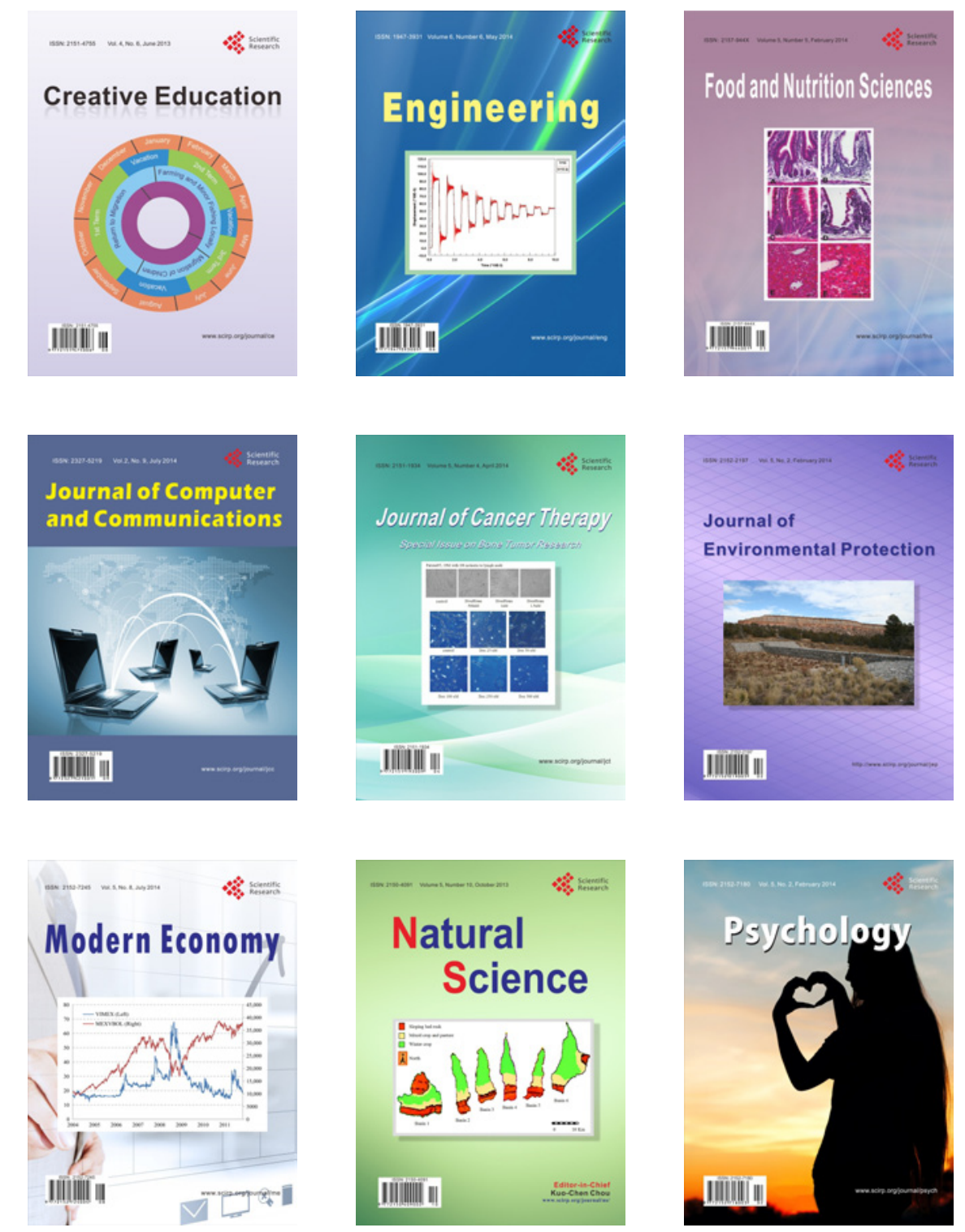